\title{
Mulemba
}

Revista Angolana de Ciências Sociais

4 (8) | 2014

Globalização, gestão e dinâmicas de desenvolvimento regional e local

\section{O racismo visto na óptica de quatro autores «lusófonos»: Notas breves a propósito do livro 0 que é o racismo?}

\section{Víctor Kajibanga}

\section{OpenEdition}

Journals

Edição electrónica

URL: http://journals.openedition.org/mulemba/314

DOI: $10.4000 /$ mulemba.314

ISSN: 2520-0305

\section{Editora}

Edições Pedago

Edição impressa

Data de publição: 1 novembro 2014

Paginação: 633-640

ISSN: 2182-6471

Refêrencia eletrónica

Víctor Kajibanga, «O racismo visto na óptica de quatro autores «lusófonos»: Notas breves a propósito do livro O que é o racismo?», Mulemba [Online], 4 (8) | 2014, posto online no dia 20 novembro 2016, consultado o 26 janeiro 2021. URL: http://journals.openedition.org/mulemba/314 ; DOI: https:// doi.org/10.4000/mulemba.314

Este documento foi criado de forma automática no dia 26 janeiro 2021.

Tous droits réservés 


\title{
O racismo visto na óptica de quatro autores «lusófonos»: Notas breves a propósito do livro 0 que é o racismo?
}

\author{
Víctor Kajibanga
}

\section{NOTA DO AUTOR}

Texto da apresentação pública da obra da autoria de Jacqueline de Jesus, Paulo de Carvalho, Rosália Diogo e Paulo Granjo, O que é o racismo? (Lisboa, Escolar Editora, 2014, 128p.), que teve lugar em Luanda, no dia 24 de Outubro de 2014, às 15h00, no anfiteatro principal da Faculdade de Ciências Sociais (FCS) da Universidade Agostinho Neto (UAN).

1 A colecção «Cadernos de Ciências Sociais», dirigida pelo sociólogo e historiador moçambicano Carlos Serra, acaba de publicar o seu 10. número intitulado 0 que é racismo?, com quatro soberbos textos, organizados do modo seguinte: «Racismo: processos psicossociais de exclusão» (pp. 11-35), da psicóloga brasileira Jacqueline de Jesus; «Racismo enquanto teoria e prática social» (pp. 37-70), do sociólogo e jornalista angolano Paulo de Carvalho; «O que é racismo, a partir do caso brasileiro» (pp. 71-91), da jornalista brasileira Rosália Diogo; e «Raça e racismo são coisas que se aprendem» (pp. 93-127); do antropólogo português Paulo Granjo. Estas contribuições, que compõem o corpo fundamental do livro em apreço, são antecedidas de uma concisa introdução de Carlos Serra, intitulada "Construção negativa do outro» (pp. 7-9), produzida pelo facto de ser o coordenador da colecção, uma participação que já se tornou hábito, porque observada desde a primeira obra da colecção que o mesmo dirige.

Trata-se de um livro actual, que se impõe pelo conteúdo dos textos que o comportam e que têm por fim explicar um dos factores estruturantes das tensões (económicas, sociais, políticas, ideológicas e culturais) nas sociedades e no mundo contemporâneo: o racismo. Na esteira do sociólogo francês, Michel Wiewiorka (2010: 249), eu diria que «já não estamos nas décadas de 1950 ou 1960, quando podia reinar a esperança de se ver declinar o 
racismo e progrediam os movimentos pelos direitos cívicos e os processos de descolonização. Pelo contrário, a modernidade actual comporta, como ontem, este lado de sombra e o fenómeno, devastador, não só não tende a desaparecer da vida social, como encontra, nas transformações contemporâneas, recursos para ressurgir sob formas clássicas ou outras, novas ou renovadas. Manifestam-se novos actores racistas sem que os antigos tenham desaparecido por completo; abrem caminho novos discursos racistas e novas práticas racistas, a par de outros mais antigos».

Confesso que na minha condição de alguém socializado a partir de uma educação da esquerda académica (concretamente, marxista), vejo a questão racial a partir das estruturas e lógicas sociais de exploração, dominação e hegemonia de determinados grupos e agrupamentos humanos em relação a outros. Interessa-me a luta de classes e grupos como fio condutor por detrás da construção económica, social, política, ideológica e cultural do racismo. No entanto, quero sublinhar que colocar as relações de dominação e hegemonia na análise da problemática do racismo, do etnicismo e da xenofia (enquanto formas de etnocentrismo), não significa considerar que o racismo é um fenómeno exclusivo dos grupos e classes dominantes. Até porque, como diria Wiewiorka, o racismo, «é muitas vezes atraente aos olhos dos pobres para ser instrumentalizado por regimes ditatoriais, fascistas ou totalitaristas, por demagogos ou partidos extremistas com forte inserção popular» (WIEWIORKA 2010: 270).

4 Apesar dos horizontes teóricos que orientam a minha visão sobre tão delicada e sensível questão social, assim como complexa problemática teórica, tenho plena consciência que todos nós, sobretudo a geração que ainda viveu no período colonial, "crescemos e vivemos em mundos onde a ideia de "raça" não apenas é bem real como relevante, nas nossas relações sociais quotidianas e na nossa memória histórica» (GRANJO 2014: 93). Daí que concorde com o coordenador da colecção, Professor Carlos Serra, quando, no prefácio à obra que apresentamos, aluda categoricamente, que «os seres humanos não nascem racistas, etnicistas ou xenofobistas. Tornam-se nisso devido às lógicas combinadas de três fenómenos: interacção social, disputa de recursos de poder e educação. É aqui que se tecem os sistemas de referência e os meandros categoriais, é aqui que crescem, se consolidam e se naturalizam os jogos de alteridade, adesão e repulsa» (SERRA 2014: 8).

5 Entrando mais concretamente no âmago do livro, os textos que o comportam procuram responder à pergunta: «O que é o racismo?» Para além da pergunta de partida 0 que é racismo?, há no livro em apreço outras perguntas que complementam àquela. «Qual é a importância do racismo contemporâneo para se entender o processo formativo das sociedades ocidentais?», questiona-se Jacqueline de Jesus; «Há racismo em Angola?», interroga-se Paulo de Carvalho. Ao referir-se especificamente à abolição formal da escravatura e à situação actual da população afro-brasileira, a jornalista brasileira Rosália Diogo interroga-se: «De qual abolição estamos falando?». Finalmente, ao situar claramente o problema na sua base científica, o antropólogo luso Paulo Granjo, não obstante a avaliação um tanto quilométrica, não deixa de se interrogar, interrogando-nos: «os cientistas bem podem insistir que as raças humanas são uma mera invenção social, mas a verdade é que a raça de cada um de nós está estampada no nosso corpo, é uma característica natural que se mete pelos olhos dentro de quem nos observa, certo?»

6 O meu objectivo, enquanto apresentador deste livro que aparece em boa hora, não é responder à pergunta de partida, nem dar respostas às perguntas acessórias que os autores formularam. 0 meu modesto contributo resume-se na apresentação de uma proposta de leitura (uma proposta de hermenêutica ou uma grelha de leitura) para melhor compreendermos o pensamento dos autores do livro. Trata-se de uma 
apresentação essencialmente dirigida aos nossos estudantes, onde procuro plasmar as ideias principais de cada um dos autores do livro. Assim...

7 Na perspectiva de Jacqueline de Jesus, psicóloga social e professora na Universidade de Brasília, «[...] As ideias racistas contemporâneas, que remontam aos primórdios do capitalismo mercantilista, foram primeiramente teorizadas na Europa da época das grandes navegações, que posteriormente se tornou a dos grandes impérios colonialistas, sob uma aparência de rigor científico que se apropriava dos progressos da Biologia, Antropologia e Linguistica da época. Anteriormente, o que fundamentava o racismo eram crenças populares e religiosas sem o respaldo de teorias científicas» (JESUS 2014: 31). Deste ponto de vista, o racismo é, concomitantemente, uma construção social, teórica, política, ideológica e cultural. Disse, há pouco, que o racismo era, também, uma construção teórica. Quero precisar que se trata de uma construção teórica sem bases científicas, pois estamos em presença de um construto fundado «na crença da superioridade de certas raças humanas, que defende o direito de estas dominarem ou mesmo exterminarem as consideradas inferiores e proibe o cruzamento da suposta raça superior com as inferiores» (ACADEMIA 2001: 3062).

8 À pergunta «o que é racismo?», Jacqueline de Jesus responde: «[...] é um conjunto de estereótipos, preconceitos e discriminações que se baseia na crença da superioridade/ inferioridade de um grupo racial ou étnico com relação a outro, em uma conjuntura de dominância social» (JESUS 2014: 16). Ademais, a análise desta autora não fica pela definição abstracta do fenómeno, quando esta observa judiciosamente: «[...] não espanta o facto de os brasileiros serem cínicos no que concerne à questão do racismo, titulando-se como "democratas raciais", enquanto o preconceito e a discriminação contra a população negra transborda em todos os âmbitos da sociedade brasileira». Ou seja: «O dito popular "só o cego não vê" representa com propriedade a percepção do racismo pelo brasileiro médio: nega-se que ele exista, apesar dos indicadores apontarem em uma direç̧ão diametralmente oposta à da negação» (JESUS 2014: 21).

Na mesma perspectiva, ao responder à pergunta o que é racismo, a jornalista afrobrasileira Rosália Diogo diz tratar-se de «um conjunto de teorias e crenças que estabelecem uma hierarquia entre as raças, entre as etnias» (DIOGO 2014: 71-72), aclarando: "Quando falo de raça, estou me referindo não ao conceito biologizado, essencialista, e sim a uma construção social» (DIOGO 2014: 73). Esta autora constata que 125 anos depois, completados no ano de 2013, da abolição da escravização de negros no Brasil, o desafio continua a ser o da legitimação «da condição libertária da população afro-brasileira» (DIOGO 2014: 81). Assim, baseando-se num estudo do Instituto de Pesquisa Económica Aplicada (IPEA), Rosália Diogo afirma que no Brasil a população negra é o segmento mais pobre da sociedade, a menos escolarizada e a que ocupa os postos inferiores no mercado do trabalho, factos que levaram o governo do antigo Presidente Luiz Inácio Lula da Silva a adoptar várias políticas de discriminação positiva a favor da população negra.

Entretanto, o contributo do antropólogo Paulo Granjo, investigador do Instituto de Investigação Social da Universidade de Lisboa e Professor da Universidade Nova de Lisboa, ressalta a importância da educação, da socialização e dos activos cognitivos nos processos de construção do racismo e do etnocentrismo. Para este autor, o racismo está intimamente ligado ao etnocentrismo. Em seu entender, o "etnocentrismo corresponde antes de mais a um efeito cognitivo que é plausivelmente inerente aos processos de construção das identidades e de percepção e conceptualização da diferença». Ele entende que nas sociedades onde crescemos e vivemos, «todos somos formatados [...] para percepcionar o 
mundo, classificá-lo, valorá-lo, conhecer as relações casuais, sentirmos e comportarmo-nos de determinadas formas» (GRANJO 2014: 115).

11 Por sua vez, o texto do sociólogo Paulo de Carvalho, «Racismo enquanto teoria e prática social» (pp. 37-70), começa por situar as origens do racismo no século XIX. Segundo este autor, «o racismo é um dos males sociais da Idade Moderna, que surgiu no século XIX». Para este, os primeiros lampejos desta teoria e desta ideologia do racismo foram lançados pelo francês Joseph Arthur de Gobineau (1816-1882), no seu livro seminal denominado Ensaio sobre a desigualdade das raças humanas, publicado em 1853. Segundo o nosso autor, inspirado na obra Racismo, etnicidade, cidadania. Reflexões sociológicas e filosóficas, do sociólogo holandês Veit-Michael Bader (2008), as teorias e práticas racista conheceram um grande incremento, «[...] com a implantação do sistema colonial em várias partes do globo e com o desenvolvimento do imperialismo moderno, sob forte influência das ideologias sociais darwinistas» (CARVALHO 2014: 37). E, mais adiante: «A colonização de África constituiu um bom pretexto para as potências colonizadoras desenvolverem a ideologia racial, justificando dessa forma não apenas a presença europeia em África, mas fundamentalmente o domínio e a subjugação das populações autóctones com base no critério racial» (CARVALHO 2014: 38).

12 À pergunta «o que é o racismo?», Paulo de Carvalho responde: «Para nós, o racismo consiste na convicção de superioridade de uma "raça" em relação às demais, estando a ela superiormente associados atitudes e comportamentos preconceituosos e discriminatórios dirigidos às "raças" consideradas "inferiores"》 (CARVALHO 2014: 38-39). Este autor associa o racismo ao preconceito racial e à discriminação, sendo esta última uma das prováveis consequências da primeira (CARVALHO 2014: 51). Entretanto, este entende que "há discriminação racial quando impedimos (ou pretendemos impedir) alguém de frequentar a nossa escola, o nosso local de trabalho, o nosso supermercado, o nosso restaurante, a nossa discoteca ou o nosso clube, apenas por pretender ou aparentar pertencer a determinado grupo racial» (CARVALHO 2014: 51). Numa outra perspectiva, o autor considera que «uma pessoa pode estar discriminada em relação aos seus direitos de cidadania, nomeadamente aos direitos políticos, direitos civis e direitos sociais» (CARVALHO 2014: 51).

13 Para Paulo de Carvalho, existem dois tipos de discriminação racial: «o racismo individual e o racismo institucional». Segundo este sociólogo, «o racismo individual inclui actos de discriminação racial feitos por indivíduos, contra pessoas. Já o racismo institucional parte das organizações e visa manter determinado grupo racial em estado de exclusão e de subordinação social» (CARVALHO 2014: 51-52).

14 À pergunta «há racismo em Angola?», Paulo de Carvalho responde que entre nós o preconceito racial «manifesta-se em duas direçôes contrárias: da parte da maioria negra para a minoria branca e vice-versa». E, mais adiante escreve: «O racismo tradicional, com a convicção e a assunção de superioridade de uma raça sobre outra, existe agora em pequena dimensão», e «não podia, aliás, ser de outra forma», observa o sociólogo, «visto que a minoria branca deixou de ter predominância no acesso ao poder político (e é este que determina em certa medida o acesso ao poder económico» (CARVALHO 2014: 57). Respostas a estas distintas questões Estas são seras são as respostas solitárias de Paulo de Carvalho à pergunta de partida e à questão do racismo em Angola.

15 Para terminar, quero parafrasear o sociólogo francês Michel Wiewiorka (2010: 262) e com ele dizer que o papel dos cientistas sociais e das ciências sociais não é por certo definir precipitadamente - por ou contra a racialização e a etnização. É, antes de mais analisar e explicar estas tendências em todas as suas dimensões, contradições e nas suas 
implicações. Do ponto de vista do estado, por exemplo, lutar pela igualdade socioeconómica é uma coisa, combater os preconceitos raciais é outra. Do ponto de vista de uma organização militante ou de activista, recusar o racismo é uma coisa, afirmar-se como actor racial ou étnico é outra. Do ponto de vista do sujeito, constituirse como indivíduo para tentar dispôr dos mesmos direitos de qualquer indivíduo é uma coisa, esforçar-se por ser reconhecido enquanto membro desta ou daquela identidade colectiva é outra. E, neste último caso, apresentar-se unicamente como vítima (do racismo passado, colonial, do tráfego negreiro, por exemplo, bem como do presente) é uma coisa, afirmar uma identidade positiva, cultural, até racial, como foi o caso da «negritude», é outra. Os dados do problema são múltiplos, mais ou menos combinantes, contraditórios e ambíguos. As respostas mais elaboradas e provavelmente, afinal, mais satisfatórias são as que tentam conciliar um máximo destes dados, articular tanto quanto possível o que parece inocente ou ambivalente; as respostas mais espectaculares, mas que conduzem a confrontos ideológicos por vezes violentos e pouco produtivos, são, pelo contrário, as que radicalizam uma só opção.

\section{BIBLIOGRAFIA}

ACADEMIA DAS CIÊNCIAS DE LISBOA, 2001, Dicionário da língua portuguesa contemporânea. Lisboa, Editorial Verbo.

BADER Veit-Michael, 2008, Racismo, etnicidade, cidadania. Reflexões sociológicas e filosóficas. Introdução de Manuel Carlos Silva. Porto, Afrontamento [«Biblioteca das Ciências Sociais: Sociologia»; 62].

GOBINEAU Joseph Arthur de, 1853-1855, Essai sur l'inégalité des races humaines, 4 vols., Paris, Didot.

WIEWIORKA Michel, 2010, Nove lições de sociologia. Como compreender um mundo em mudança. Lisboa, Editorial Teorema.

WIEWIORKA Michel, 2010, «O retorno do racismo», in Nove lições de sociologia. Como compreender um mundo em mudança. Lisboa, Editorial Teorema, pp. 249-279.

\section{AUTOR}

\section{VÍCTOR KAJIBANGA}

vika.vm95@gmail.com

Professor Titular e Decano da Faculdade de Ciências Sociais da UAN. Director da Mulemba Revista Angolana de Ciências Sociais (Luanda), da Revista Angolana de Sociologia (Luanda), e Coordenador da colecção «Reler África» das Edições Mulemba.

Sociólogo, é diplomado, mestre e doutor em Sociologia pela Universidade Estatal de Moscovo «Lomonosov». É Professor Titular na Universidade Agostinho Neto (UAN), Decano da Faculdade de Ciências Sociais (FCS) da UAN, investigador do Centro Avançado de Estudos Africanos (CAEA) da FCS, investigador do Centro de Estudos Africanos (CEA) da Universidade do Porto, investigador 
do Centro de Estudos Africanos do ISCTE (Lisboa) e Presidente da Sociedade Angolana de Sociologia (SASO). Foi Vice-Reitor da UAN e Decano do Instituto Superior de Ciências da Educação (ISCED) de Luanda. Além de inúmeros artigos, é autor da obra

A alma sociológica na ensaística de Mário Pinto de Andrade. Uma introdução ao estudo da vida e obra do primeiro sociólogo angolano (Luanda, 2000). 